\title{
What Do You Think About Your Dreams? The Construction of a Belief About Dreams Questionnaire
}

This article was published in the following Dove Press journal:

Nature and Science of Sleep

\author{
Peihuan $\mathrm{Li}^{1}$ \\ Feilong Yang ${ }^{2}$ \\ Xiang Wang $\left(\mathbb{D}^{3}\right.$ \\ Rui Yao ${ }^{4}$ \\ Ji Dai ${ }^{5}$ \\ Yunlong Deng (iD) ${ }^{1,2}$ \\ 'Department of Clinical Psychology, The \\ Third Xiangya Hospital, Central South \\ University, Changsha, Hunan 4I00I3, \\ People's Republic of China; \\ ${ }^{2}$ Psychosomatic Health Institute, The \\ Third Xiangya Hospital, Central South \\ University, Changsha, Hunan 4I00I3, \\ People's Republic of China; ${ }^{3}$ Medical \\ Psychological Center, The Second \\ Xiangya Hospital, Central South \\ University, Changsha, Hunan 4I00II, \\ People's Republic of China; ${ }^{4}$ Center for \\ Psychological Development and Service, \\ Hunan University of Chinese Medicine, \\ Changsha, Hunan, 410208, People's \\ Republic of China; ${ }^{5}$ Mental Health \\ Education Center, Hunan University of \\ Technology and Business, Changsha, \\ Hunan 410205, People's Republic of \\ China
}

Correspondence: Yunlong Deng Department of Clinical Psychology, The Third Xiangya Hospital, Central South University, No. 138 Tongzipo Road, Yuelu District, Changsha, Hunan 4I00I3,

People's Republic of China

Tel $+86|8975| 86 \mid 78$

Fax +8673188618487

Email deng0087@I26.com
Background and purpose: Nightmare distress (ND) is associated with a broad spectrum of psychopathological conditions such as anxiety, depression and bipolar disorder. Some studies have indicated that dream beliefs play an important role in the occurrence and treatment of nightmare distress. However, existing instruments used to assess dream beliefs either fail to satisfy the requirements of the psychometrics or fail to capture the essence of dream beliefs. This research pursued two objectives: (1) to develop a questionnaire, called the Beliefs About Dreams Questionnaire (BADQ), to measure beliefs people hold about their dreams and (2) to describe the dream beliefs of Chinese college students.

Methods: The structure and items on the BADQ were based on the previous literature and were the result of an open questionnaire. Some items were deleted through expert review and the result of predict test. To evaluate its validity and reliability, a sample of 1408 Chinese college students from two universities answered the BADQ, the Chinese version of Van Dream Anxiety Scale (CVDAS), the Dream Survey Questionnaire (DSQ), the Patient Health Questionnaire-9 (PHQ-9) and the Generalized Anxiety Disorder-7(GAD-7) Questionnaire. After two weeks, 95 of them answered the BADQ again. Exploratory factor analysis $(n=704)$ and confirmatory factor analysis $(n=704)$ were conducted to explore and verify the structure of BADQ. The correlation between the CVDAS and the BADQ was calculated to evaluate the divergent validity.

Results: The BADQ contains 26 items. Exploratory factor analysis indicated a five-factor structure: Dream omen and health, Dream superstitions, Dream meaninglessness, Dream reality, and Dream attitude. The result of the confirmatory factor analysis also supported the five-factors structure. Acceptable internal consistency (Cronbach's $\alpha$ of all subscales exceeded 0.80 ) and ordinary to moderate test-retest reliability (the intraclass correlation coefficient of all subscales ranged from 0.467 to 0.713 ) of the BADQ were presented. Low degree correlation between the CVDAS and the BADQ (ranged from to -0.052 to 0.219 ) showed that they were two different variables, indicating a good divergent validity.

Conclusion: The present investigation revealed moderate to high construct validity and reliability of the BADQ.

Keywords: dream beliefs, nightmare distress, scale construction, Chinese population

\section{Introduction}

Nightmares are disturbing dreams that involve unpleasant emotions such as anxiety, fear, sadness, anger, and desperation and result in abrupt awakenings. ${ }^{1,2}$ A number of studies have suggested that the frequency and distress of nightmares are related to a broad spectrum of mental health disorders. ${ }^{3-7}$ Nightmare distress (ND) refers to 
the waking suffering or distress associated with nightmares, ${ }^{8,9}$ which mainly consists of sleep-related complaints and daytime dysfunction. ${ }^{10}$ With the deepening of the research, numerous researchers have pointed out that compared with nightmare frequency (NF), ND is more closely related to psychopathology, ${ }^{8,9,11,12}$ especially for psychological disorders marked by a high level of negative affect (eg, anxiety and depression). ${ }^{13,14}$

In the field of ND, Belicki believes that ND partly arises from the people's views and their evaluation of their dreams after they wake up. ${ }^{9}$ In one of his studies, he interviewed people with frequent nightmare but different level of ND, and he found that high-distress people regarded their nightmares more seriously, paid more attention to their nightmares, and were less likely to dismiss their nightmare as merely dreams (e.g., they see nightmares as a sign that something bad will happen). ${ }^{9}$ Furthermore, researchers also found that in the treatment of nightmares, ND can be effectively reduced by modifying the beliefs about dreams (e.g., that what happens in dreams will come true). In a treatment study for Posttraumatic Stress Disorder (PTSD), nightmare distress was reduced by psychoeducation, which allowed beliefs about dreams to be corrected. ${ }^{15}$ In a clinical treatment of nightmares, Belicki taught nightmare sufferers to modify their beliefs about nightmares (instead of attempting to reduce nightmare frequency) and found that ND was alleviated. ${ }^{16}$ As mentioned above, we know that people's beliefs about dreams play an important role in the occurrence and treatment of nightmare distress.

Besides, the associations between dream beliefs and other variables (e.g., dream recall frequency, dream content, physical health, personality, and treatment effect) also indicated the importance of dream beliefs. Some researchers suggested that those who regarded dreams as meaningful and valuable reported a higher dream recall frequency. ${ }^{17-19}$ Hall's study suggested that people who deemed dreams have no meaning tended to be creative and think independently. ${ }^{20}$ King and Decicco found that individuals who hold the belief that dreams reflect their physical health reported more body parts in their dreams and showed significantly lower physical functioning, and people who were indifferent to their dreams actually reported higher levels of well-being. ${ }^{21}$ Furthermore, people who believed that dreams contained information about spiritual beliefs reported fewer misfortunes in their dreams, and they scored higher on meta-personal self-construal. ${ }^{21} \mathrm{~A}$ therapy patient who views dreams as symbolic and psychological will gain more useful information from his or her dream during psycho-analytical treatment. ${ }^{22}$ Several studies have found gender differences concerning dream beliefs; usually, females have a more positive attitude toward their dreams than males, and they are more likely to believe that dreams have some special functions, such as reflecting our daily life or carrying a message from God or the devil. ${ }^{19,23-25}$ In conclusion, dream beliefs are important, and it is necessary for us to be concerned with them.

Nowadays, several questionnaires and scales are used to study dream beliefs. Hall developed a 35-items Dream Belief Questionnaire (DBQ), which contained eight types of dream beliefs. ${ }^{20}$ However, in this scale, two subscales (mystical and religious) had a similar meaning. For example, "I believe that a dream can carry a message from the spirit world (mystical)" and "I believe that a dream can contain a spiritual or religious message (religious)". It is inappropriate that two similar dimensions appear in one scale. Dominic et al developed the Inventory of Dream Experiences \& Attitude (IDEA) to assess dream beliefs. ${ }^{26}$ Some of the 50 items measured dream beliefs, and other items measured dream content and dream recall. It is known that dream recall and content do not figure into dream beliefs; therefore, this questionnaire cannot accurately capture the importance of dream beliefs. Mazandarani et al developed the Iranian version of the Dream Belief Questionnaire, called My Beliefs About Dream Questionnaire (MBDQ). ${ }^{27}$ MBDQ contained 25 items and identified six subscales. However, the last subscale "Dreams as essential to health," only had two items, which does not meet the requirements of psychometrics. ${ }^{28}$ Furthermore, except for "Dream as carrying a message", the internal consistency coefficient for the other five subscales were found to be 0.65 or lower, suggesting that these factors are somewhat heterogeneous. ${ }^{29}$ At present, only one dream attitude scale has been used in China, but this scale has not been standardized. ${ }^{30}$ As mentioned above, the existing instruments are subject to shortcomings. Since ancient times, China has a keen interest and a unique view about dreams. It is worthwhile to develop a new questionnaire that combines the existing achievements with Chinese native culture to measure Chinese people's beliefs about dreams.

This research pursued two main objectives: (1) to develop a questionnaire, the Beliefs about Dreams Questionnaire (BADQ), to measure beliefs people hold about their dreams. (2) to describe the dream beliefs of Chinese college students. For the purposes of this study, dream beliefs are defined as people's views on dreams, including whether dreams having meanings, and what these meanings are. 


\section{Methods}

\section{Scale Design and Development}

In formulating the dimensions of dream beliefs, we made use of existing measures of dream beliefs. We excluded the dimensions that are not related to the dream beliefs, and added dimensions based on the literature to create our preset dimensions: Dream omen (e.g., I believe that what I have dreamed may happen), Dream reality (e.g., I believe that dream contents are linked with my experiences), Dream creativity (e.g., I believe that a dream can inspire me), Dream health (e.g., I believe that dreams are related to a dreamer's health and mood state), Dream superstition (e.g., I believe that we can communicate with people who have passed away through dreams), Dream learn (e.g., I believe that dreams can consolidate memories), and Dream attitude (e.g., I like dreaming).

Items were compiled in three ways. First, many the items are based on previous scales measuring beliefs about dreams, such as the BDQ, the IDEA and the MADQ. Second, we reviewed Chinese classical literature, refined the description of dreams in Chinese culture, and then compiled some items. Third, we developed an open questionnaire and surveyed 150 college students, and some items were added using the results of the open questionnaire. This led to the original version of the Beliefs about Dreams Questionnaire, which included 52 items describing different beliefs about dreams.

To ensure the content validity of the questionnaire, 14 psychologists were invited to evaluate the questionnaire. They modified the wording of some items, deleted the duplicated items, and ensured that the sentences are simple and easy to understand. Finally, 29 items were left. These 29 items were tested by 128 college students, and none of the items were deleted after the item analysis. There were no any sentences that were difficult to understand.

The instructions were

Some attitudes and beliefs about dreams follow. Please read them carefully and state your opinion (to what extent you agree or disagree) on each sentence. Please answer the question according to your general attitude and opinion in most cases.

The response format entailed a five-point Likert-type scale reflecting similarity ratings ( $1=$ strongly disagree, $2=$ disagree, $3=$ neutral or do not know, $4=$ agree, $5=$ strongly agree).

\section{Participants}

The cluster stratified random sampling method was used to conduct a collective survey in two universities (Hunan Business University and Hunan University of Chinese Medicine). The participants included 1600 undergraduate students: 1408 (606 males, 802 females) fully completed the questionnaires. The effective return ration was $88 \%$. The mean age of the sample was $19.39(\mathrm{SD}=1.63)$, with ages ranging from 16 to 25 . We randomly divided the subjects into two equal groups using the SPSS algorithm. The first group, for exploratory analysis, consisted of 704 people, and the second group, for confirmatory analysis, consisted of 704 people. In order to examine the test-retest reliability of the BADQ, 110 students were randomly chosen for a second round of testing after two weeks, and 95 completed the BADQ. Participants under the age of 18 years not required parental content to join in this research. The research protocol was approved by the local ethics committee. The study was conducted in accordance with the Declaration of Helsinki.

\section{Procedure}

All participants were informed of the purpose and content of the study, and informed consent was obtained. Participants used their break time or elective course time to complete the questionnaire. The questionnaire takes $15-20$ mins to complete. All materials were collected within two weeks.

\section{Measures \\ Dream Survey Questionnaire}

An original Dream Survey Questionnaire (see Appendix) was developed and utilized; items were selected from the Mannheim Dream Questionnaire ${ }^{31}$ and Sleep and Dream Questionnaire. ${ }^{4}$ Dream recall frequency was measured with a question requiring participants to estimate the number of dreams typically recalled per week. To determine nightmare and bad dream frequency, two seven-point scales $(1=$ never, $2=$ less than once a month, $3=$ about once a month, $4=$ about two to three times a month, $5=$ about once a week, $6=$ several times a week, $7=$ almost every morning) were used.

\section{The Chinese Version of Van Dream Anxiety Scale (CVDAS)}

We used the Chinese version of Van Dream Anxiety Scale (CVDAS) to measure ND. The CVDAS is an assessment instrument that can evaluate dream anxiety caused by nightmare. Wang et al tested its reliability and validity in a Chinese population. ${ }^{14}$ The contents of CVDAS include 
most impacts of nightmares on health, such as sleep problems, morning anxiety, psychological problems, impairment of daytime functioning, and autonomic symptoms. The CVDAS consists of 17 items, among which four items (items 7-10) are used to collect clinical information and are not included in the total scores, and the remaining 12 items are rated on a five-point Likert scale ranging from 0 (never) to 4 (often). Item 5 is related to autonomic hyperactivity and consists of 12 symptoms. Each of the 12 symptoms is also rated on a $0-4$ scale. If the total score obtained for the 12 symptom scores is between 0 and 10 , the sum score of this item is 0 ; if it is between 11 and 20, it is 1 ; if it is between 21 and 30 , it is 2 ; if it is between 31 and 40 , it is 3 ; and if it is between 41 and 48 , it is 4 . Thus, the scores for the 13 items are summed up to yield a global CVDAS score of $0-52$. The CVDAS showed excellent internal consistency (Cronbach's $\alpha$ coefficient was 0.926 ) and good test-retest reliability (the intraclass correlation coefficient was 0.942 ).

\section{The Patient Health Questionnaire-9 (PHQ-9)}

Depression will be assessed using the patient health questionnaire (PHQ-9). The PHQ-9 consists of nine items. All items are rated on a four-point scale (ranging from 0 to 3 ), with higher total scores indicating more severe depression (scores of 5-9, 10-14, 15-19 and $\geq 20$ indicate mild, moderately severe, and severe depression, respectively). ${ }^{32}$ The PHQ-9 demonstrates high internal consistency (Cronbach's $\alpha$ between 0.86 and 0.89 ) and high test-rest reliability (ICC between 0.84 and 0.95 ). ${ }^{32-34}$ The Chinese version of the PHQ-9 is a nine-items, self-reported inventory that has shown good reliability and validity (Cronbach's $\alpha=0.86$ ). ${ }^{33}$

\section{The Generalized Anxiety Disorder-7 (GAD-7) Questionnaire}

Anxiety will be assessed using the generalized anxiety disorder-7 questionnaire (GAD-7). It is a seven-item selfreported scale which is used to measure the severity of generalized anxiety disorders. ${ }^{35}$ All items are rated on a fourpoint scale; the total score ranges from 0 to 21 . Scores of 5-9, $10-14$ and $\geq 15$ indicate mild, moderate, and severe anxiety, respectively. ${ }^{35}$ The GAD-7 has shown good validity and reliability in several languages (Cronbach's $\alpha$ between 0.89 and 0.92). ${ }^{35-37}$ The Chinese version of GAD-7 showed an excellent internal consistency (Cronbach's $\alpha$ coefficient was 0.898 ) and good test-retest reliability (the intraclass correlation coefficient was 0.856$){ }^{37}$

\section{Data Analysis}

SPSS24.0 and Amos23.0 were used to analyze data. The exploratory factor analysis (EFA), using principal axis factoring (PAF) and Promax rotation, was employed to explore the factor structure. Meanwhile, Amos 23.0 was used to perform confirmatory factor analysis (CFA) to verify the structural validity of the questionnaire. Means and standard deviations of the BADQ and the correlation between the factors were calculated. To study the internal consistency of the BADQ, the Cronbach' $\alpha$ was calculated. Intra-class correlation coefficient (ICC) was used to analysis the test-retest reliability. The correlation between the CVDAS and of the BADQ was calculated to test the divergent validity of BADQ.

In addition to the basic reliability and validity analysis, we also did some auxiliary analysis. In order to verify if there were gender differences between participants on dream beliefs, an independent-samples $t$-test was computed. To better understand the variation and variability of BADQ, a hierarchical cluster analysis was used. The cluster analysis, which allows for the systematic identification, organization, and description of behavioral patterns observed within a group of individuals, ${ }^{38}$ was performed on group participants based on similarities in the types of dream beliefs. The Ward method and Euclidean distance were used for computing cluster analysis. ${ }^{38}$ The final clusters were identified based on interpretability of clusters and also based on the significant difference between two clusters. Next, an independent-samples $t$-test or analyses of variance (ANOVAs) were used to compare the difference between dream beliefs and various variables (e.g., nightmare distress, nightmare and bad dream frequency, dream recall frequency, and psychopathology).

\section{Results}

\section{Item Analyses}

There were no items that produced an extreme means, and there were not any items that showed a $75 \%$ endorsement of a single Likert response. Items 11,12 , and 14 were dropped due to redundancy (they were correlated 0.612 , $0.630,0.721$ with other items). The total scores of all items in the questionnaire were ranked from low to high. The first $27 \%$ were selected as the low group and the last $27 \%$ as the high group. The mean values of the two groups on the same question were tested for differences, and all items reached a significant level. 


\section{Validity}

\section{Structure Validity}

The EFA was performed on scores from a randomly selected subsample $(n=704)$. The significance of Bartlett's test of sphericity was observed $\left(\chi^{2}=9680.23\right.$, $\mathrm{p}<0.001)$. The KMO value was 0.914 , which was considered perfect. ${ }^{39}$ These results suggested that the factor analysis was appropriate. The final analysis, which produced the best solution, was comprised of 26 items. As is seen in Table 1, five factors were extracted (based on an eigenvalue $>1$ and scree criterion). In totally, these factors accounted for a total of $63.88 \%$ of the variance in item responses (Factor $1=32.24 \%$, Factor $2=13.08 \%$, Factor $3=8.78 \%$, Factor $4=5.26 \%$ and Factor 5=4.51\%). According to the results of the EFA and the content of the five factors, the five factors were labeled as follows: Factor 1 (7 items): Dream omen and health, Factor 2 (6 items): Dream superstition, Factor 3 (5 items): Dream meaninglessness, Factor 4 (4 items): Dream reality, Factor 5 (4 items): Dream attitude.

The CFA was conducted on the remaining members of the sample $(n=704)$ using maximum likelihood estimation

Table I Factor Loadings for BADQ Items in Pattern Matrix

\begin{tabular}{|c|c|c|c|c|c|}
\hline Item Number and Description & $\begin{array}{l}\text { Dream Omen } \\
\text { and Health }\end{array}$ & $\begin{array}{l}\text { Dream } \\
\text { Superstition }\end{array}$ & $\begin{array}{l}\text { Dream } \\
\text { Meaninglessness }\end{array}$ & $\begin{array}{l}\text { Dream } \\
\text { Reality }\end{array}$ & $\begin{array}{l}\text { Dream } \\
\text { Attitude }\end{array}$ \\
\hline 20. I believe that dreams are a sign of something. & 0.651 & 0.210 & 0.048 & 0.061 & 0.107 \\
\hline $\begin{array}{l}\text { 18. I believe that dreams are related to a dreamer's health } \\
\text { and mood state. }\end{array}$ & 0.629 & -0.187 & -0.056 & -0.197 & -0.012 \\
\hline 16. I believe that dream content can enlighten my real life. & 0.618 & 0.060 & -0.072 & -0.021 & 0.119 \\
\hline 19. I believe that images in dreams are symbolic. & 0.564 & 0.194 & -0.065 & 0.006 & 0.147 \\
\hline 2I. I believe that what we dreamed may happen. & 0.555 & 0.259 & 0.001 & -0.016 & 0.010 \\
\hline 17. I believe that dreams can affect mental health. & 0.476 & -0.079 & 0.013 & -0.011 & 0.013 \\
\hline 23. I believe that dreams can inspire and enlighten me. & 0.441 & 0.070 & -0.031 & -0.068 & 0.133 \\
\hline $\begin{array}{l}27 . \text { I believe that dreams are the enlightenment to people } \\
\text { from gods or devils. }\end{array}$ & -0.128 & 0.875 & 0.040 & -0.051 & 0.027 \\
\hline 26. I believe that dreams are the source of superpowers. & 0.006 & 0.834 & 0.000 & -0.010 & -0.030 \\
\hline 29. I believe that dreams can reflect my previous lives. & 0.005 & 0.793 & 0.018 & 0.001 & 0.019 \\
\hline $\begin{array}{l}\text { 28. I believe that dreams are my experiences in another } \\
\text { parallel world. }\end{array}$ & 0.035 & 0.751 & 0.006 & -0.015 & 0.082 \\
\hline $\begin{array}{l}25 . \text { I believe that we can communicate with people who } \\
\text { have passed away through dreams. }\end{array}$ & 0.023 & 0.733 & -0.011 & -0.022 & 0.026 \\
\hline $\begin{array}{l}\text { 24. I believe that dreams are connected with the activity of } \\
\text { the soul. }\end{array}$ & 0.310 & 0.541 & -0.108 & -0.068 & -0.065 \\
\hline $\begin{array}{l}\text { I5. I believe that dreams are the product of random neural } \\
\text { firing and nothing more. }\end{array}$ & 0.012 & -0.046 & 0.834 & -0.094 & -0.047 \\
\hline 13. I believe that people who believe in dreams are stupid & -0.034 & 0.004 & 0.806 & -0.009 & 0.042 \\
\hline I0. I do not pay attention to my dreams at all. & 0.014 & 0.022 & 0.742 & -0.012 & -0.015 \\
\hline 04. I believe that any dreams are totally unreal, and illusory. & 0.072 & 0.004 & 0.661 & 0.150 & 0.052 \\
\hline $\begin{array}{l}\text { 22. I do not believe dreams can influence people in life in } \\
\text { any form. }\end{array}$ & -0.036 & 0.014 & 0.435 & -0.047 & -0.046 \\
\hline 02. I believe that dream content links with my experiences. & 0.115 & 0.032 & 0.003 & -0.769 & -0.011 \\
\hline $\begin{array}{l}\text { 0I. I believe that what you dream about at night reflects } \\
\text { what you think about during the day. }\end{array}$ & -0.072 & 0.023 & -0.011 & -0.749 & 0.030 \\
\hline 03. I believe that dreams can reflect the real life. & 0.089 & 0.128 & 0.008 & -0.607 & 0.108 \\
\hline $\begin{array}{l}05 . \text { I agree on that dream can reflect people's } \\
\text { subconsciousness. }\end{array}$ & 0.130 & -0.066 & -0.035 & -0.400 & 0.372 \\
\hline 08. I would like to talk to others about my dreams. & -0.003 & 0.049 & -0.012 & 0.079 & 0.855 \\
\hline 07. I like dreaming. & -0.042 & -0.065 & -0.035 & -0.090 & 0.766 \\
\hline $\begin{array}{l}06 . \text { I believe that dreaming is one of the most important } \\
\text { ways to learn about yourself. }\end{array}$ & 0.110 & -0.020 & -0.010 & -0.170 & 0.644 \\
\hline 09. I would like to recall my dreams. & 0.099 & 0.091 & -0.025 & 0.017 & 0.605 \\
\hline
\end{tabular}

Note: Bold data indicates which factor the items belong to. 
Table 2 Comparison of Fitting Indexed for Models I and $2(\mathrm{~N}=704)$

\begin{tabular}{|l|l|l|l|l|l|l|l|}
\hline & $\chi^{2}$ & df & $\chi^{2}$ /df & RMSEA & GFI & CFI & IFI \\
\hline Model I & 973.65 & 265 & 3.67 & 0.062 & 0.896 & 0.928 & 0.929 \\
Model 2 & 916.69 & 264 & 3.47 & 0.059 & 0.903 & 0.934 & 0.934 \\
\hline
\end{tabular}

to evaluate the fitness of the EFA identified five-factor model. Generally, the cut-offs for acceptable fit are $\chi^{2}$ / $\mathrm{df} \leq 5, \mathrm{RMSEA} \leq 0.08$ and GFI, CFI and $\mathrm{IFI} \geq 0.9 .{ }^{40}$ As is shown in Table 2, the five-factor model (model 1) did not fit the data well. We therefore modified the model according to the item contents and modification index. Both item 17 ("I believe that dreams can affect mental health") and item 18 ("I believe that dreams are related to a dreamer's health and mood state") belonged to Factor 1: Dream omen and health. Both of the two items were associated with health, so the error correlation between item 17 and 18 was acceptable. After setting the error of these two items as free estimation, model 2 was established, and the CFA was conducted again. As is seen in Table 2, model 2 fitted the data well.

Pearson correlations between the factors of the BADQ were calculated (Table 3), ranging from -0.251 (Dream meaninglessness and Dream attitude) to 0.656 (Dream omen $\&$ health and Dream attitude). Just as we expected, Dream meaninglessness was negatively correlated with the other four factors.

\section{Divergent Validity}

The divergent validity of the scale was evaluated through the examination of correlations between the BADQ and the CVDAS (see Table 3). Both the BADQ and then CVDAS are used to measure dreams, but the former focuses on beliefs and the latter focuses on subjective distress. A low correlation with other confounding variables indicates good divergent validity. ${ }^{41}$ The four factors of BADQ were found to show consistently positive correlations of low magnitude with the ND measure of the CVDAS ( $r=0.150$ for Dream omen and health, $r=0.219$ for Dream superstitions, $\mathrm{r}=0.050$ for Dream reality and $\mathrm{r}=0.125$ for Dream attitude). Dream meaninglessness was negatively correlated with CVDAS $(r=-0.052)$ in a low magnitude. These findings indicated that the BADQ had good divergent validity.

\section{Reliability}

Internal consistency was evaluated by Cronbach's $\alpha$. The alpha reliabilities of all BADQ factors were high, they ranging from 0.821 to 0.902 , which was acceptable ${ }^{29}$ (Dream omen and health: $\alpha=0.848$, Dream superstition: $\alpha=0.902$, Dream meaninglessness: $\alpha=0.821$, Dream reality: $\alpha=0.836$, and Dream attitude: $\alpha=0.868$ ) (see Table 3 ).

The test-retest reliability was tested by ICC. ${ }^{42}$ The reliability coefficients for the Dream omen and health, Dream superstition, Dream meaninglessness, Dream reality and Dream attitude were $0.713,0.467,0.521,0.497$ and 0.505 , respectively, reflecting ordinary to moderate stability for these factors ${ }^{43}$ (see Table 3 ).

\section{Gender Differences}

An independent-samples $t$-test was used to examine the beliefs about dream across genders. As is seen in Table 4, except for Dream attitude, females obtained significantly higher scores than males across the rest of the four factors.

\section{Dreamer Profiles Differences}

Two distinct profiles were elucidated. In total, 412 participants (29.3\% of the sample) are Indifferent Dreamers: they believe that dreams have no real meaning. The remaining 996 participants $(70.3 \%$ of the sample) are Interested Dreamers: they consider dreams to be meaningful. As can be seen in Table 5, except for Dream meaninglessness, Interested Dreamers obtained significantly higher scores

Table 3 Pearson Intercorrelations Between BADQ Factors, Reliability and Divergent Validity

\begin{tabular}{|c|c|c|c|c|c|c|c|}
\hline & I & 2 & 3 & 4 & 5 & $\boldsymbol{\alpha}$ & ICC \\
\hline I. Dream omen and health & - & & & & & 0.848 & 0.713 \\
\hline 2. Dream superstition & $0.470 * *$ & - & & & & 0.902 & 0.467 \\
\hline 3. Dream meaningless & $-0.223 * *$ & $-0.045^{*}$ & - & & & 0.821 & 0.521 \\
\hline 4. Dream reality & $0.588 * *$ & $0.281 * *$ & $-0.179 * *$ & - & & 0.836 & 0.497 \\
\hline 5. Dream attitude & $0.656 * *$ & $0.380 * *$ & $-0.25 \mathrm{I} * *$ & $0.626 * *$ & - & 0.868 & 0.505 \\
\hline 6. CVDAS & $0.150 * *$ & $0.219 * *$ & -0.052 & 0.050 & $0.125^{* *}$ & & \\
\hline
\end{tabular}

Notes: ${ }^{*} p<0.05, * * p<0.01$

Abbreviations: CVDAS, the Chinese version of Van Dream Anxiety Scale; ICC, interclass correlation coefficient. 
Table 4 Mean Score for Males and Females and Gender Difference for Each Factor of BADQ

\begin{tabular}{|l|l|l|l|l|}
\hline Factors & $\begin{array}{l}\text { Total } \\
\text { Sample } \\
(\mathbf{n}=1408)\end{array}$ & $\begin{array}{l}\text { Female } \\
(\mathbf{n}=802)\end{array}$ & $\begin{array}{l}\text { Male } \\
(\mathbf{n}=606)\end{array}$ & t-test \\
\hline $\begin{array}{l}\text { Dream omen } \\
\text { and health }\end{array}$ & $22.16(4.36)$ & $22.43(3.94)$ & $21.81(4.84)$ & $2.652^{* *}$ \\
\hline $\begin{array}{l}\text { Dream } \\
\text { superstition }\end{array}$ & $15.31(4.43)$ & $15.52(4.19)$ & $15.04(4.71)$ & $1.99 *$ \\
\hline $\begin{array}{l}\text { Dream } \\
\text { meaninglessness }\end{array}$ & $13.77(3.65)$ & $14.14(3.49)$ & $13.29(3.78)$ & $4.35^{* *}$ \\
\hline Dream reality & $13.25(3.09)$ & $13.46(2.88)$ & $12.98(3.33)$ & $2.94 * *$ \\
\hline Dream attitude & $12.62(3.17)$ & $12.68(3.30)$ & $12.57(3.07)$ & 0.66 \\
\hline
\end{tabular}

Notes: $*_{p}<0.05,{ }^{*} *_{p}<0.01$.

Table 5 Comparison Between Different Dreamers Profiles

\begin{tabular}{|c|c|c|c|}
\hline & $\begin{array}{l}\text { Indifferent } \\
\text { Dreamers }\end{array}$ & $\begin{array}{l}\text { Interested } \\
\text { Dreamers }\end{array}$ & $t$-test \\
\hline $\begin{array}{l}\text { Dream omen } \\
\text { and health }\end{array}$ & $|8.3|(4.33)$ & $23.76(3.23)$ & $-25.93^{* *}$ \\
\hline $\begin{array}{l}\text { Dream } \\
\text { superstition }\end{array}$ & II.72 (3.45) & $16.80(3.91)$ & $-22.89 * *$ \\
\hline $\begin{array}{l}\text { Dream } \\
\text { meaninglessness }\end{array}$ & I4.57 (3.74) & $13.44(3.55)$ & $5.36 * *$ \\
\hline Dream reality & 10.93 & $|4.2|(2.63)$ & $-20.68^{* *}$ \\
\hline Dream attitude & $9.67(2.46)$ & I3.84 (2.58) & $-28.01 * *$ \\
\hline DRF & $2.74(2.53)$ & $4.06(3.77)$ & $-2.85^{*}$ \\
\hline BDF & $2.89(1.23)$ & 3.31 (I.48) & $-4.23 * *$ \\
\hline NF & $2.42(1.02)$ & $2.65(1.23)$ & $-2.79 *$ \\
\hline CVDAS & $4.50(6.04)$ & $6.29(7.31)$ & $-4.37^{* *}$ \\
\hline PHQ-9 & $8.24(5.31)$ & $9.91(5.56)$ & $-5.17^{* *}$ \\
\hline GAD-7 & $5.92(4.43)$ & 7.31 (4.98) & $-4.93 * *$ \\
\hline
\end{tabular}

Notes: $* p<0.05, * * p<0.01$

Abbreviations: DRF, dream recall frequency; $B D F$, bad dream frequency; $N F$, nightmare frequency; CVDAS, the Chinese version of Van Dream Anxiety Scale; PHQ-9, the Patient Health Questionnaire-9; GAD-7, the Generalized Anxiety Disorder-7 Questionnaire.

than Indifferent Dreamers across the other four factors. The $t$-test showed a significant difference between the two profiles on DRF and in the frequency of bad dreams/ nightmares. The Indifferent Dreamers showed lower level of nightmare distress, depression and anxiety than Interested Dreamers, as measured by the CVDAS, PHQ9 and GAD-7, respectively.

\section{Discussion}

In the present study, a multidimensional scale of belief about dreams was developed. The BADQ consisted of five factors and assessed beliefs about dreams. The hypothesized Dream creativity did not emerge in this analysis. The final factors, which included Dream omen and health, Dream superstition, Dream meaninglessness, Dream reality and Dream attitude all showed adequate internal consistency, two-weeks test-retest reliability, and divergent validity. The differences in beliefs about dreams between males and females were examined. A hierarchical cluster analysis was used to divide the participants into two categories, and the Indifferent Dreamers showed higher levels of well-being than the Interested Dreamers.

\section{Factor Interpretations}

The results of the EFA and CFA provided support to the allocation of the items to the five factors. We titled Factor 1 as Dream omen and health, and it had 15\% variance. This factor consisted of seven items expressing the underlying idea that dreams can foretell the future and can reflect upon one's health. This is in line with the views of ancient Chinese thinkers and medical experts on dreams: medical experts believed that the main function of dreams was to reflect people's health, and thinkers believed that the function of dreams was mainly to predict good or bad luck. ${ }^{44}$ In ancient China, most people believed that dreams could foretell the future. There were professional dream interpreters and specialized books (such as the Duke of Zhou) that helped people to interpret the meaning of their dreams. Even today, there are still many people who explain their dreams using the book above. In addition, the earliest Chinese medical classics (such as Huangdi's Classic on Medicine) explained the relationship between dreams and physical health: for example, if a person was weak, he/she would dream of water; and if the person was strong, he/she would dream of fire. ${ }^{45}$ In Western dream theory, dreams also have these two functions. ${ }^{46,47}$

The second factor was Dream superstition with six items. This factor was related to people's beliefs that dream are closely connected to spiritual dimensions. People who scored high on this factor usually believed that dreams could reflect their previous lives and the activity of their soul. At the same time, they agreed that they could communicate with Bodhisattva, ghosts, and the dead through dreams. This factor was similar to both 
"Dream Guidance" in IDEA and "Carrying message" in MBAD. In ancient China, there were many literary works describing the dream superstitions. Ghosts, Bodhisattva and deceased people enter people's dreams, make confessions, reveal the truth to clear up injustices, warn, and persuade people to be good. ${ }^{48}$ In the famous Chinese story "Injustice to Dou E", Dou appeared to her father in a dream and said, "I was wrongfully killed, please find out the truth". Her father investigated and was able to wash away the grievances of Dou E. ${ }^{49}$ Western prescientific dream theories saw dreams as messages coming from outside the individual, mostly from god-like creatures. ${ }^{46}$

Factor 3 (Dream meaninglessness) comprised five items. Meaninglessness was similar to Hobson's view on dreams: he asserted that dreams are the result of limbic activity and have no meaning. ${ }^{50}$ People who scored high in this factor tended to believe that dreams had no impact on their life; consequently, they did not pay attention to their dreams. No research regarding this belief has been conducted in China. A Canadian study showed that only $6.5 \%$ of the participants thought that dreams are meaningless. ${ }^{21}$

We named the Factor 4 as Dream reality, which was analogous to the Dream Continuity of IDEA. The four items in this factor assessed people's beliefs that the content of their dreams is related to waking-life experiences and that dreams could reflect conscious and unconscious desires. ${ }^{21,51}$ A number of patients believed that daytime problems played an important role in their dreams. ${ }^{52}$ There is a saying in China that men do not dream of giving birth and women do not dream of bows and arrows. This is because that they have not experienced these events and, therefore, did not dream about them. ${ }^{45}$ At present, some research supports the "continuity hypothesis", that is, that the content of dreams reflects waking activities. ${ }^{53,54}$

The last factor is Dream attitude with four items concerning people's attitude about dreams. This factor contains items about whether participants are willing to remember their dreams, whether they are willing to share their dreams, and whether they like or dislike dreams. Only one study in China focused on the attitude towards dreams, and it found that the positive attitudes towards dreams can predict individuals' willingness to engage in psychoanalytic interpretation therapy. ${ }^{30}$

\section{Reliability}

The result of the current study indicated that the BADQ was a reliable test for the measurement of dream beliefs. According to Cuieford, alpha coefficients greater than 0.70 are acceptable. ${ }^{29}$ The alpha coefficients in this study for all factors were good to excellent (0.821-0.902). As all alpha coefficients in the current study were greater than 0.80 , the BADQ possessed stronger internal consistency than the MADQ, which had yielded factor alphas below 0.50.

The retest results after two weeks showed that the retest correlation of the five factors of BADQ ranged from 0.467 to 0.713 . A phenomenon that may affect retest reliability in the fact that we often have different views about different dreams. For example, if I dream of being rich, I hope it will come true. However, if I lose money in a dream, I will decide that the dream is fake. It is likely that participants had different dreams between the two tests, leading to ordinary $(0.41<\mathrm{ICC}<0.60)$ retest reliability.

\section{Validity}

The results of the current study suggest that the BADQ exhibited high levels of factorial validity. First, the degree of intercorrelation observed among the five factors ranged from weak (Dream meaninglessness/Dream superstition: -0.045 ) to moderate (Dream omen and health/Dream attitude: 0.656) suggesting that the factors were related but distinct. Dream meaninglessness was significantly negatively correlated with the other four factors. Second, the results of the confirmatory factor analysis indicated that the BADQ five-factor model provided a good fit of the data.

For the divergent validity, we calculated the Pearson correlation between dream beliefs and CVDAS. A Low degree of correlation showed that they were two different variables, indicating good divergent validity.

\section{Gender Difference}

When compared with males, females elicited higher scores in Dream omen and health, Dream superstition, Dream meaninglessness, and Dream reality; males and female showed similar scores in Dream Attitude. Females were more likely to agree that dreams had special functions, such as foretelling the future and reflecting mental and physical health, ${ }^{27,46,55}$ which was the exact was the content of the Dream omen and health dimension. This study observed the same phenomenon. In the present study, females scored higher than males in Dream superstition, which was consistent with the previous result. ${ }^{26,27,46} \mathrm{We}$ also found that females scored higher than males in Dream meaninglessness. It was interesting that on the one hand, females agreed that dreams were meaningless, but on the other hand, they agreed that dreams had special functions 
as well. However, in previous studies, males generally found that dreams have no particular meaning. In Dominic's study, he suggested that females were more likely to agree that dreams reflected our daily lives than males, ${ }^{26}$ and we got the same result. Among the five factors, Dream attitude are the most studied. A lot of research has focused on attitudes towards dreams, and it has suggested that females generally have a more positive attitude towards dreams than males. ${ }^{19,23-25}$ In this study, although females scored higher than males, the difference was insignificant.

\section{Dream Profiles}

As shown in the results, most of the participants (70.3\%) are Interested Dreamers. The MADQ and this questionnaire have a similar structure: Mazandarani et al divided the Iranian participants into two groups using the same method (Convinced Dreamers and Unconvinced Dreamers). However, the Convinced Dreamers, who held the view that dreams are meaningful, only accounted for $57.0 \%{ }^{27}$ Perhaps it is the strong culture of dream interpretation atmosphere in China that makes most people consider their dreams are meaningful. In future research, we can compare the differences in dream belief questionnaires (eg, BADQ and MADQ) between different regions and countries to explore cultural differences.

Furthermore, the results suggested that Interested Dreamers have a higher dream frequency (both bad dreams and nightmares) and a lower level of psychological health. What is the relationship between the frequency of nightmares/bad dreams, the belief about dreams and well-being? Maybe, as Dominic speculated, psychological distress makes people pay attention to all aspects of themselves, increasing people's sensitivity and interest in their dream experiences. ${ }^{26}$ Or, as well as affecting health, maybe frequent bad dreams and nightmares give people more insight into the dream itself and its content. In any case, we can know that the beliefs about dreams can reflect people's health status.

\section{Limitations and Directions for Future Research}

The primary limitation of this research is the employment of a student sample. Such a sample may not be representative of individuals within the community or patients who suffer from nightmares, thus affecting the generalizability of our results. Besides, participants in this sample are of similar age and education; however, previous research has shown that people of different ages and education levels had different beliefs about dreams. Further research should examine the psychometric properties of the BADQ in samples more representative of the general population. Second, the design was crosssectional, making it impossible to draw conclusions about the causality of the relationship between dream beliefs and psychological health. Does pre-existing dream beliefs influence psychological health or psychological health contribute to people's increased sensitivity and interest in their dream? In order to figure out this question, longitudinal studies are needed.

\section{Ethical Approval}

The Institutional Review Board (IRB) of The Third Xiangya Hospital in Hunan approved the study (2019-S255).

\section{Acknowledgments}

We would like to thank Miss Yin Meng and Miss Li Siya for their help in data collection.

\section{Disclosure}

The authors declared no conflicts of interests in this work.

\section{References}

1. Simor P, Horváth K, Gombos F, et al. Disturbed dreaming and sleep quality: altered sleep architecture in subjects with frequent nightmares. Eur Arch Psychiatry Clin Neurosci. 2012;262(8):68 7-696. doi:10.1007/s00406-012-0318-7

2. Zadra A, Pilon M, Donderi DC. Variety and intensity of emotions in nightmares and bad dreams. J Nerv Ment Dis. 2006;194(4):249-254. doi:10.1097/01.nmd.0000207359.46223.dc

3. Ross L, Gary F. Nightmare prevalence, nightmare distress, and self-reported psychological disturbance. Sleep. 2002;25(2):205-212.

4. Zadra A, Donderi DC. Nightmares and bad dreams: their prevalence and relationship to well-being. J Abnorm Psychol. 2000;109(2):27 3-281. doi:10.1037/0021-843X.109.2.273

5. Ohayon MM, Moreslli PL, Guilleminault C. Prevalence of nightmares and their relationship to psychopathology and daytime functioning in insomnia subjects. Sleep. 1997;20(5):340-348. doi:10.1093/sleep/20.5.340

6. Nagy T, Salavecz G, Simor P, et al. Frequent nightmares are associated with blunted cortisol awakening response in women. Physiol Behav. 2015;147:233-237. doi:10.1016/j.physbeh.2015.05.001

7. Tanskanen A, Tuomilehto J, Viinamaki H, et al. Nightmares as predictors of suicide. Sleep. 2001;24(7):844-847.

8. Mark B, Laura F, Elvira W. The relationship of nightmare frequency and nightmare distress to well-being. J Sleep Res. 2004;13(2):12 9-136. doi:10.1111/j.1365-2869.2004.00394.x

9. Belicki K. Nightmare frequency versus nightmare distress relations to psychopathology and cognitive style. J Abnorm Psychol. 1992;101 (3):592-597. doi:10.1037/0021-843X.101.3.592

10. Böckermann M, Gieselmann A, Pietrowsky R. What does nightmare distress mean? Factorial structure and psychometric properties of the Nightmare Distress Questionnaire (NDQ). Dreaming. 2014;24(4):27 9-289. doi:10.1037/a0037749 
11. Samara M, Hazel M, Tammy TN, et al. Nightmare distress and stress-related health problems. Percept Mot Skills. 1999;89:114-115. doi:10.2466/pms.1999.89.1.114

12. Martina K, Reinhard P. Behavioral effects of nightmares and their correlations to personality patterns. Dreaming. 2001;11:43-52. doi:10.1023/A:1009468517557

13. Wood JM, Bootzin RR. The prevalence of nightmares and their independence from anxiety. J Abnorm Psychol. 1990;99:64-68. doi:10.1037/0021-843X.99.1.64

14. Wang X, Dai LS, Yin M, et al. The factor structure, reliability and validity of the Chinese version of the Van Dream Anxiety Scale. Neuropsychiatr Dis Treat. 2019;15:57-67. doi:10.2147/NDT.S192891

15. Krakow B. Nightmare therapy: emerging concepts from sleep medicine. In: Glucksman MKM, editor. Dream Reearch: Contributions to Clinical Practice. New York (NY, US): Routledge/Taylor \& Francis Group; 2015:149-160.

16. Belicki K, Belicki D. A cognitive-behavioral strategy for reducing distress associated with nightmare. Assoc Study Dreams Newsl. 1986;3:3-4.

17. Cernovsky ZZ. Dream recall and attitude toward dreams. Percept Mot Skills. 1984;58:911-914. doi:10.2466/pms.1984.58.3.911

18. Beaulieu-Prévost D, Zadra A. Dream recall frequency and attitude towards dreams: a reinterpretation of the relation. Pers Individ Dif. 2005;38(4):919-927. doi:10.1016/j.paid.2004.06.017

19. Michael S, Carola N, Stefanie W. Dream recall, attitude toward dreams,and personality. Pers Individ Dif. 1996;20(5):613-618. doi:10.1016/0191-8869(95)00216-2

20. Hall DH. Beliefs about dreams and their relationship to gender and personality [dissertation]. Berkeley (CA): Wright Institude Graduate School of Psychology; 1996.

21. King DB, DeCicco TL. Dream relevance and the continuity hypothesis: believe it or not? Dreaming. 2009;19(4):207-217. doi:10.1037/ a0017612

22. Alex W. Dream: The Unconsicous and Analytical Therapy. San Francisco: CG Jung Institue; 1971.

23. Schredl M. Positive and negative attitudes towards dreaming: a representative study. Dreaming. 2013;23(3):194-201. doi:10.1037/ a0032477

24. Schredl M. Factors influencing the gender difference in dream recall frequency. Imagin Cogn Pers. 2002;22(1):33-39. doi:10.2190/JR55WYC2-1GC0-023D

25. Paul RR, Roland HT. Interest in dreams and dream recall. Percept Mot Skills. 1988;66:291-294. doi:10.2466/pms.1988.66.1.291

26. Beaulieu-Prévost D, Charneau Simard C, Zadra A. Making sense of dream experiences: a multidimensional approach to beliefs about dreams. Dreaming. 2009;19(3):119-134. doi:10.1037/a0017279

27. Mazandarani AA, Aguilar-Vafaie ME, Domhoff GW. Iranians' beliefs about dreams: developing and validating the my beliefs about dreams questionnaire. Dreaming. 2018;28(3):225-234. doi:10. 1037/drm0000085

28. Wu ML. Questionnaire Statistical Analysis Practice SPSS Operation and Application. 2nd ed. Chongqin: Chongqin University Press; 2010.

29. Zwaanswijk W, Veen VC, Vedder P. The youth psychopathic traits inventory: a bifactor model, dimensionality, and measurement invariance. Assessment. 2017;24(7):932-944. doi:10.1177/1073191116632340

30. Chen K, Shen HY. A survey on Chinese college student's attitude toward dreams and their preference for a dream analysis session based on analytical psychology. J Nanjing Normal Univ. 2011;4:101-104.

31. Schredl M, Brres S, Klingauf A, et al. The Mannheim Dream questionnaire (MADRE): retest reliability, age and gender effects. Int J Dream Res. 2014;7(2):141-147.

32. Spitzer RL, Kroenke K, Williams JB. Validation and utility of a self-report version of PRIME-MD: the PHQ primary care study. Primary care evaluation of mental disorders. Patient health questionnaire. JAMA. 1999;282(18):1737-1744. doi:10.1001/jama.28 2.18.1737
33. Wang W, Bian Q, Zhao Y, et al. Reliability and validity of the Chinese version of the Patient Health Questionnaire (PHQ-9) in the general population. Gen Hosp Psychiatry. 2014;36(5):539-544. doi:10.1016/j.genhosppsych.2014.05.021

34. Lotrakul M, Sumrithe S, Saipanish R. Reliability and validity of the Thai version of the PHQ-9. BMC Psychiatry. 2008;8(1). doi:10.1186/ 1471-244X-8-46

35. Spitzer RL, Kroenke K, Williams JB, et al. A brief measure for assessing generalized anxiety disorder: the GAD-7. Arch Intern Med. 2006;166(10):1092-1097. doi:10.1001/archinte.166.10.1092

36. Kertz S, Bigda-Peyron J, Bjorgvinsson T. Validity of the generalized anxiety disorder-7 scale in an acute psychiatric sample. Clin Psychol Psychother. 2012;20(5):456-464. doi:10.1002/cpp.1802

37. Zeng QZ, He YL, Liu H, et al. Reliability and validity of Chinese version of the Generalized Anxiety Disorder 7-item (GAD-7) scale in screening anxiety disorders in outpatients from traditional Chinese internal department. Chin Mental Health J. 2013;27(3):163-168.

38. Borgen FH, Barnett DC. Applying cluster analysis in counseling psychology research. J Couns Psychol. 1987;34(4):456-468. doi:10.1037/0022-0167.34.4.456

39. Spicer J. Makeing Sense Multivariate Data. Thousand Oaks (CA): SAGE Publications; 2005.

40. Hu LT, Bentler PM. Cutoff criteria for fit indexes in covariance structure analysis: conventional criteria versus new alternatives. Struct Equation Model. 1999;6(1):1-55. doi:10.1080/10705519909 540118

41. Dai HQ. Psychometrics. 2nd ed. Beijing: Higher Education Press; 2005.

42. Shrout PE, Fleiss JL. Intraclass correlations: uses in assessing rater reliability. Psychol Bull. 1979;86(2):420-428. doi:10.1037/00332909.86.2.420

43. Shrout PE. Measurement reliability and agreement in psychiatry. Stat Methods Med Res. 1998;7(3):301-317. doi:10.1177/0962280298 00700306

44. Wang FY. The psychology of dream interpretation in ancient China. J Nanjing Normal Univ. 1997;3:91-94.

45. Liu WY. The exploration of dreams in ancient China. Social Sci Front. 1983;4:32-39.

46. Olsen MR, Schredl M, Carlsson I. People's views on dreaming: attitudes and subjective dream theories, with regard to age, education, and sex. Dreaming. 2016;26(2):158-168. doi:10.1037/drm0000020

47. Castle Ve Castle RL. Our Dreaming Mind. New York: Ballentine; 1994.

48. Luo SR, Liu J. Analysis on reasons and social significance of dreaming ghosts or gods in San Yan. J Xinyu Univ. 2017;22(1):58-61.

49. Gao ZM. Probe further into the soul that appears in one's dream \& make a request. J Humanities Social Sci. 2003;23(4):72-74.

50. Hobson JA, McCarley RW. The brain as a dream state generator: an activationsynthesis hypothesis of the dream process. Am J Psychiatry. 1977;132(12):1335-1348.

51. Nell W. Contemporary dream beliefs and practices: a qualitative, sociological study. South Afr Rev Sociol. 2014;45(1):122-139. doi:10.1080/21528586.2014.887918

52. Schredl M, Kleinferchner P, Gell T. Dreaming and personality: thick vs. thin boundaries. Dreaming. 1996;6(3):219-223. doi:10.1037/ h0094456

53. Schredl M, Hofmann F. Continuity between waking activities and dream activities. Conscious Cogn. 2003;12(2):298-308. doi:10.1016/ S1053-8100(02)00072-7

54. Domhoff GW. The Scientific Study of Dreams. Washington (DC): American Psychological Association; 2007.

55. Valášek M, Watt C. Individual differences in prophetic dream belief and experience: exploring demographic and sleep-related correlates. Pers Individ Dif. 2015;87:65-69. doi:10.1016/j. paid.2015.07.028 


\section{Publish your work in this journal}

Nature and Science of Sleep is an international, peer-reviewed, open access journal covering all aspects of sleep science and sleep medicine, including the neurophysiology and functions of sleep, the genetics of sleep, sleep and society, biological rhythms, dreaming, sleep disorders and therapy, and strategies to optimize healthy sleep.
The manuscript management system is completely online and includes a very quick and fair peer-review system, which is all easy to use. Visit http://www.dovepress.com/testimonials.php to read real quotes from published authors. 